\title{
A Corpus-Driven Study of the Multimodal Representational Characteristics of Chinese Children's Denial
}

\author{
Rongbin Wang, Qian Zhang \\ School of Foreign Languages, Shanxi University, Taiyuan, China \\ Email address: \\ rongbinwang@163.com (Rongbin Wang), 1161234147@qq.com (Qian Zhang)
}

\section{To cite this article:}

Rongbin Wang, Qian Zhang. A Corpus-Driven Study of the Multimodal Representational Characteristics of Chinese Children's Denial. International Journal of Language and Linguistics. Vol. 9, No. 3, 2021, pp. 110-119. doi: 10.11648/j.ijl1.20210903.18

Received: May 17, 2021; Accepted: May 28, 2021; Published: June 2, 2021

\begin{abstract}
As multimodal communication develops by leaps and bounds, children's multimodal act has increasingly attracted attention, which makes understanding systematically multimodal act of children become essential. This quantitative study analyzes the multimodal characteristics of Chinese children's acts of denial through observing 110 cases of multimodal denial acts of a Mandarin-speaking boy as a case study from the perspective of Multimodal Discourse Analysis. As is shown, compared with verbal denial and non-verbal denial, multimodal denial employed by the target boy occupies the largest proportion of $74.5 \%$, and the most common inter-semiotic relationship is equivalence, accounting for $66 \%$, rather than complementary or supplementary interaction. What's more, the frequencies of the target boy's denial toward the three groups of interlocutors, that is, the elders, the peers and the non-relatives, are different, and denial against the elders as the most common includes 61 cases making up 55.4\%, among which the frequency of denial toward the mother takes the first position. By figuring out the characteristics of multimodal denial of the target boy and drawing corresponding implications, this paper endeavors to provide some instructive suggestions to parenting. In daily communication with children, parents need to pay enough attention to children's multimodal acts and react accordingly and properly with both verbal and non-verbal sources so as to create an efficient communication, which are conducive to some positive parent-child education and interaction.
\end{abstract}

Keywords: Chinese-Speaking Children, Acts of Denial, Multimodal Discourse Analysis

\section{Introduction}

Nowadays, as multimodal communication is more prevalent in society, children's multimodal act gets more concerned and encouraged to better adapt to social environment. Multimodal denial as a negative act will also become an important communicative ability to effectively express person's feelings. Thus analyzing children's multimodal denial to find out its characteristics is necessary. This study tries to figure out that through 110 denial cases of a Mandarin-speaking boy.

Denial is a statement whereby an allegation is explicitly or implicitly declared that something is untrue [1]. However, denial is also a common communicative act from the perspective of social semiotics. Multimodal denial refers to denial that is represented through multiple semiotic modals such as verbal language, facial expressions, body languages, gestures and so on. In this paper, the Mandarin-speaking child under discussion often chooses at least one semiotic modal to express the meaning of denial, or in other words, to constitute the act of denial. Within different contexts, the Chinese child employs different modals to express the meaning of denial when faced with different interlocutors. Although traditionally speaking, denial has a negative communicative force, as a kind of social act it also deserves thorough research. Being confronted with prejudice or intending to rectify others' opinions, children may express their denial to show their self-confidence, courage and their independent ideas, or to spread the truth of a certain case.

This paper studies the characteristics of a 14-year-old Mandarin-speaking boy's multimodal denial acts. Based on a quantitative corpus analysis, this paper studies the frequency of each case denial conducted by the target boy and the interactional cross-modal relationships. At the same time, the paper also analyzes the frequency of denial according to the types of different interlocutors in detail. Finally, from these aspects, the paper summarizes the characteristics of Chinese children's multimodal denial acts, hoping to provide some 
useful implications with regard to the ways of parent-child education and interaction.

\section{Literature Review}

The word "Denial" is defined as "a statement that something is not true", "a refusal of something requested or desired" and "an action of declaring something to be untrue" in Collins Cobuild Advanced Learner's English-Chinese Dictionary ( $8^{\text {th }}$ Edition) [2]. The target of denial might also be metalinguistic and this metalinguistic denial constituted a kind of "the device that could oppose the previous speech on any ground" [3]. At first glance, denial may have some negative influences, according to the politeness principles; take a closer look, exposure to such denials may enhance individuals' critical thinking ability to curtail the spread of rumors [4, 5]. Denial also makes individuals more cautious about information processing acts $[5,6]$. Previous researches of denial by and large paid attention to analysis from the perspective of pragmatics, for instance, Spenader \& Maier pointed out that denial differed from the speech act of assertion because it did not add new information, but rather retracted information [7]. Its function was to oppose the previous discourse, that is, to delete the previously introduced material from the common ground [8]. Sandt held that denial should not be confused with negative sentences [9]. Even if denial often included negation (such as no, not), it was actually a non-monotonous speech act [9]. He found that denial could be made without negation [9]. Kearns (2006) pointed out that a conditional denial was an illocutionary act which was a meaningful action through expression, then he developed a logical system designed to capture (and explain) the use of conditional sentences for conditional denial [10]. Ho discussed the performance of denial in the comment response genre--management responses to address negative online comments made by dissatisfied customers, and summarized that denial, whether used alone or in series, could aim at the asserted information, the rationality of customers, the responsibility of hotels and the seriousness of problems [1]. From the perspective of social semiotics, Oversteegen \& Schilperoord (2014) explored some possibilities of visual negation and found that the essence of visual negation or denial was to some extent paradoxical to make it highly prominent by not displaying objects or attributes [11]. Bressem \& Müller (2014) studied a set of gestures like sweeping away, holding away, throwing away and brushing away used by Germans in expressing negative acts such as denial [12]. Bressem et al. (2017) analyzed two repetitive gestures in German: "sweeping away" and "holding away", and showed that the semantic core of these two gestures was consistent with their specific referential and pragmatic meanings [13].

It can be seen from the above review that current researches on denial are far more than sufficient, and most analysis are done from the perspective of pragmatics. On top of that, a handful of studies are on the denial of pictures and gestures but research on children's multimodal denial is quite rare. This paper studies the characteristics of multimodal denial of a Mandarin-speaking boy, especially focusing on two research questions: First, what are the general distributional characteristics of the use of different semiotic modals, and second, how the use and interactional relationships of different semiotic modals differs as the interlocutor changes?

\section{Theoretical Framework}

This article builds up its theoretical framework on the basis of Systemic Functional Grammar and Social Semiotics.

According to the theory of Systemic Functional Grammar, context is mainly divided into cultural context and situational context $[14,15]$. Halliday regards situational context as an instance of cultural context, a context that produces text, and he believes that situational context consists of three variables: field, tenor and mode [16]. The field of discourse refers to what happened and what activities, etc. [16]; Tenor refers to who interacts with whom, and what is the role relationship of them [16]; Mode of discourse refers to the role of language and other modals in the context [17].

In this study, the field refers to natural talks during the target boy interacting with different interlocutors. Based on the tenor in the context of multimodal situations, this study analyzes the target boy's multimodal denial of different interlocutors and divides them into three groups: the elders, the peers and the non-relatives, which are subdivided into denial of his mother, his stepfather, his elder sister, his younger brother, his friends and etc. Mode under discussion relates to the usage of multimodal sources and other informal resources of the target boy.

According to Matthiessen, the context of multimodal discourse echoes the situational context of language [17]. The context of multimodal discourse is mainly manifested in the expression level, that is, the meaning of the text is a whole, but it is embodied by different types of modals selected from a variety of modal systems [17]. In other words, within a multimodal context, meaning is realized through the cooperation of different semiotic modals rather than through mono modal, that is, different semiotic modals appropriately interact with one another in a certain cultural and situational context to represent certain meaning and realize some act. Besides, different contexts motivate the choice of various meanings and modals, that is, context provides motivation for interaction [18].

Halliday holds that language is a kind of social symbol, through which meaning can be expressed [15]. Besides language, there are also many semiotic modals representing meanings such as facial expressions, gestures and embodied acts. This paper studies multimodal acts of denial of a Mandarin-speaking child, based on the point of view of semiotics, denial is divided into verbal denial, non-verbal denial and multimodal denial. Verbal denial are realized by way of mere verbal expressions using negative expressions such as "bu shi"/ "bu" (no), "bu neng"(cannot), etc. Non-verbal denial refers to denials realized by non-verbal semiotic resources such as frowning or grinning. Multimodal denial refers to the usage of verbal and non-verbal sources 
together to conduct the act of denial like saying " $b u$ shi" and in the meantime wrinkling brows. In the process of conducting acts of denial, people choose to use one modal or more modals from the multimodal system where contains a lot of meaning potentials, and then a specific form of modal or modal combination is chosen according to the context, tenor and other factors. The following figure shows the specific use of modals in children's multimodal denial.

Through analyzing the acts of Italian children, Capirci et al. found that there were three kinds of interactional relationships among different modals: equivalent, complementary and supplementary [19]. An equivalent relationship refers to the simultaneous usage of typical negative expression and conventional negative nonverbal modals [19]; a complementary relationship refers to the distribution of negative acts (negation act itself and the negation object) in verbal and nonverbal modal respectively, and those two modals complete a negative act together [19]; a supplementary relationship refers to the reinforcement of verbal negation by rhythmic nonverbal modals [19].

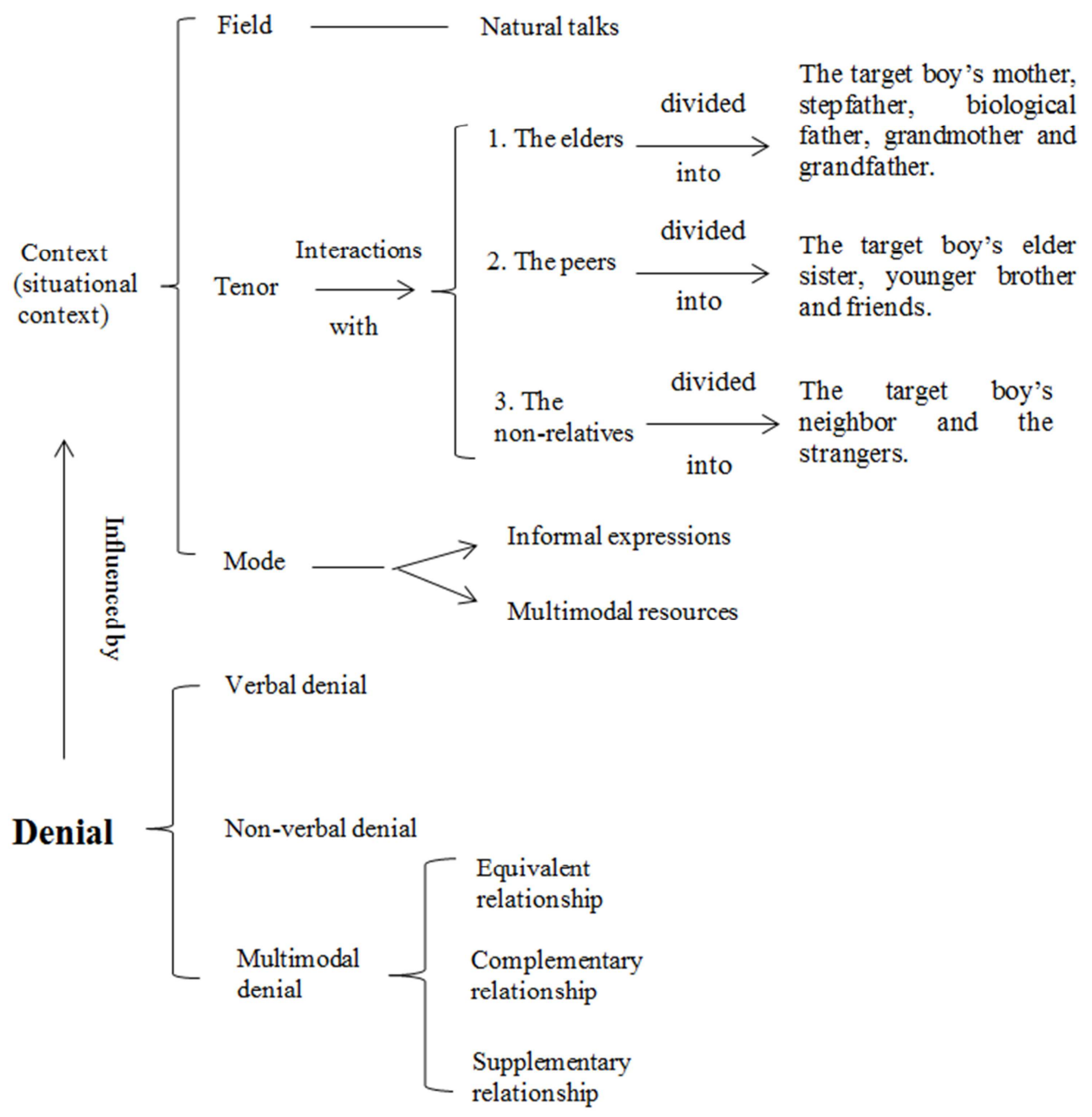

Figure 1. Analytical framework of a Mandarin-speaking boy's denial acts.

\section{Corpus Collection and Annotation}

In this study, a 14-year-old Mandarin-speaking boy was selected as the object of analysis, and the video collection was from a family comedy which mainly tells series of humorous happenings among members of a family. Since the comedy are filled with multimodal interactions between family members, namely three children and their parents, and the dialogues in the play were designed to be quite similar to daily communications, for the reason of which this comedy was selected as the corpus for the current study. 63 hours of video corpus were collected and watched through thoroughly and among those 195 cases of negation identified in the corpus, there are 110 cases of denial.

According to the types of models used, 110 cases are first classified as verbal denials, non-verbal denials and multimodal denials, the transcription of which were respectively highlighted with different colors for the sake of further statistical analysis. Then, 110 cases are further classified into three different groups according to the types of interlocutors: Group 1, the elders which includes the target boy's parents, his grandfather and his grandmother, Group 2, the peers which involves his elder sister, his younger brother and his friends, and Group 3, the non-relatives. Statistical analysis was conducted to find answers to the two research questions above and tables are drawn. 


\section{Results and Discussion}

\subsection{General Distributional Characteristics of the Use of Different Semiotic Modals}

Table 1. Denial with regard to semiotic modals used.

\begin{tabular}{lll}
\hline Denials & Frequency & Percentages \\
\hline Multimodal denial & 82 & 74.6 \\
Verbal denial & 24 & 21.8 \\
Non-verbal denial & 4 & 3.6 \\
Total & 110 & 100 \\
\hline
\end{tabular}

As can be seen from Table 1, 110 cases of denial are identified and analyzed, among which multimodal denial is the most frequent form, accounting for 74.6 percent of the total; verbal denial comes next at 21.8 percent; nonverbal denial occurs the least frequently ( 3.6 percent). In the first place, the fact that multimodal denial tops the ranking reveals that the target boy is to a large extent able to use verbal sources and body movements freely and flexibly and combine them to conduct the act of denial with ease. This is different from what happens in early stage of development when, for example, children aged 1.5-2 years old use more mere nonverbal sources to conduct acts of negation such as showing disagreement by turning the head [20]. This contrast is actually expectable. While growing up into the period of teenagers, children have acquired enough language competence and are also more proficient in using multimodal resources to express their thoughts and emotions and conduct social acts subconsciously appropriately. And various modals accompany or reinforce each other, the communicative force of which is stronger than the use of mono modal. The power of multimodal interaction is derived from the integration of different meta-functional capabilities that are accessed to create meanings that would not be possible if one resource is used alone [21]. Secondly, that nonverbal denial accounts for the least shows that the target boy does not show any preference to conduct the act of denial merely through nonverbal signs. This result is also understandable. While verbal language is the most common and widely spread way of communication, nonverbal denial is relatively less conventionalized and may not fully reflect the meaning of denial within some contexts, which fails to conduct the act of denial and makes other interlocutors confused. In fact, over-4-year-old children without mental disorders should already have passed the period of focusing on pure and non-conventional gestures to express negation [22]. On top of those, the act of denial itself is to state or declaim that something is not true. Hence, it is understandable to see that the number of nonverbal denials is the least among 110 cases in this study. After analyzing the frequency of the three kinds of denial, this paper continues to analyze how the target boy conducted the act denial differently according to the change of interlocutors which are divided into the elders, the peers and the non-relatives.

\subsection{The Multimodal Representation of Denial with Regard to Different Interlocutors}

Table 2. Denials with regard to different interlocutors.

\begin{tabular}{lll}
\hline Interlocutors & Frequency & Percentages \\
\hline The elders & 61 & 55.5 \\
The peers & 47 & 42.7 \\
The non-relatives & 2 & 1.8 \\
Total & 110 & 100 \\
\hline
\end{tabular}

It can be seen from Table 2 that the number of denials toward the elders is the highest among 110 cases (55.5\%), while the number of denials toward the peers is 47 cases, making up $42.7 \%$ of the total, and there are only 2 cases of denial toward the non-relatives, accounting for $1.8 \%$.

\subsubsection{The Multimodal Representation of the Target Boy's Denial Toward the Elders}

As is shown, denials toward the elders are the most common (61 cases). This high frequency partially results from the situation that the target boy under discussion, a junior high school student, is regarded as being gregarious, naughty with poor academic performance at school. Hence, the target boy is usually the one being most disciplined and wronged by his parents, the elders as interlocutors in this study. In other words, high frequency of being questioned is one of the factors that lead to the target boy's frequent denial toward the elders accordingly.

Among 61 cases, there are 31 cases of denial toward the mother, 21 cases toward the stepfather, 4 cases of toward the biological father, 3 cases toward the grandmother and 2 cases toward the grandfather.

Table 3. Denials toward the mother.

\begin{tabular}{lll}
\hline Denials & Frequency & Percentages \\
\hline Multimodal denial & 24 & 77.4 \\
Verbal denial & 6 & 19.4 \\
Non-verbal denial & 1 & 3.2 \\
Total & 31 & 100 \\
\hline
\end{tabular}

The cases of denial toward the mother occur most frequently. One possible reason is that the mother herself happens to blame the target boy much more often than others. For example, whenever the mother finds that some child is getting into trouble, she immediately thinks of the target boy doing something bad or wrong and then gives the target boy castigation, as a result of which the target boy has been wronged by the mother for quite a few times. Faced with improper treatment and accusation, the target boy frequently denies in different ways immediately. It can be seen from Table 3 that multimodal denial toward the mother is the most common, followed by verbal denial and non-verbal denial.

In Example 1, both the target boy and the mother were attending a scientific presentation held in the community. The professor was introducing cloning technology on the platform, and everyone was listening carefully, while the target boy sat expressionlessly next to the mother with his eyes closed. The mother reminded him not to sleep, and then the target boy, with his eyes wide open and raising eyebrows, explained that 
he didn't sleep but was thinking. In this example, the target boy utilizes two syntactically complete sentences to denial which are not negative sentences but opposite with the mother's utterance. Verbal expressions are dominant sources which are accompanied with facial expressions, such as opening his eyes and raising eyebrows, and those facial expressions that have no negative meaning when used alone are used in this context to reinforce the verbal denial. The target boy uses verbal resources and facial expressions simultaneously to express denial, representing a supplementary semiotic interaction.

Example 1

Mother: Liu Xing, why did you fall asleep again?

The target boy: I was not asleep. I was thinking.

Multimodal: Opening his eyes wide and raising his eyebrows

In Example 2, when everybody was sitting together to have breakfast in a summer morning, the target boy was wearing thick coats experiencing astronaut's life, because he wanted to be an astronaut. Seeing that, the mother said what the target boy did was nonsense, but the target boy employed a verbal modal to deny the mother and claimed that what he did was actually serious. In this example, the target boy only used two complete utterances, one being obviously a negative sentence while another being not, but both sentences expressed a denial stance to the mother.

\section{Example 2}

Mother: What on earth are you doing on this hot day?

The target boy: I'm not joking. I'm doing something serious.

Example 3 shows the target boy's nonverbal denial of the mother. The target boy saw the mother trimming vegetables for cooking, and then grumbled that the mother didn't cook meat for him. However, the mother quipped that he would not grow taller any way. In this example, the target boy expresses his denial by pursing his lips and glancing away, which is a non-verbal denial to the mother. To a certain extent, pursing lips is now a widely accepted convention expressing denial, disapproval or displeasure, so it is understandable why the target boy utilizes this facial expression to denial in this case.

Example 3

Mother: No matter what you eat, you won't grow taller any way.

The target boy: Multimodal: Pursing lips and glancing at elsewhere.

Table 4. Denial toward the stepfather.

\begin{tabular}{lll}
\hline Denials & Frequency & Percentages \\
\hline Multimodal denial & 16 & 76.2 \\
Verbal denial & 5 & 23.8 \\
Non-verbal denial & 0 & 0 \\
Total & 21 & 100 \\
\hline
\end{tabular}

The target boy's stepfather is a director of children's plays. As a humorous, tolerant and intelligent man, he is depicted as a modest gentleman with elegant demeanor. Different from the mother, the stepfather's parenting is more persuasive, more euphemistic and emphasizes the evidence rather than wronging others at will. This interlocutional factor probably explicates that the target boy's denials toward the stepfather is not as frequent as toward the mother. There are 21 cases, of which 16 cases are multimodal denial and 5 cases are verbal ones.

In Example 4, the target boy took part in a repair competition where he won the trophy of the Repair Master. This time he was extremely glad to get the prize because he had never won any prize before. When he showed off the trophy to his stepfather, his stepfather joked with him of actually winning a lower prize. The target boy quickly pointed to the trophy correcting that with frowning. In this case, the target boy humorously used three complete sentences to avoid threatening his stepfather's face. He says those words "look at these two words" which are accompanied by fingering the trophy, verbal words and the gesture together exhibited the fact that he did won the first prize. In this case, it is not verbal expressions but the facial expression of frowning that indicates denials.

\section{Example 4}

Stepfather: OK, Barber Master Liu Xing.

The target boy: Open your big eyes and have a good look at these two words. It's called "Repair Master".

Multimodal: Frowning and pointing to trophy.

Example 5 shows the target boy's verbal denial toward the stepfather. The target boy wanted to be a soldier. Fortunately, a leader of the army appreciated him and assumed he was cut out to be a soldier. However, the mother didn't want him to do that for his young age and mischief, so she discussed with her husband trying to impede the target boy's plan. Example 5 is one of the few cases of verbal denial in which the target boy used a rhetorical question and quoted PLA's utterances to prove that the opinions of his parents were untrue. In this example, he applies mono verbal resources to conduct the act of denial.

\section{Example 5}

Stepfather: Mom and I don't think your personality is suitable for being a soldier.

The target boy: Why isn't my personality suitable? The PLA said that I am smart and quick to act.

\subsubsection{The Multimodal Representation of the Target Boy's Denial Towards the Peers}

Among 110 cases of denials, there are 47 denials toward the peers, including 19 denials toward the boy's elder sister, 17 denials toward his younger brother and 11 denials toward his friends. The denial toward the peers are mainly about denials of the latter's judgement. For example, when the target boy was talking about his admirable rock singer, his elder sister commented, "Why does it sound like a wolf to me? ", which was misjudgment in the boy's eyes and was denied with a rhetorical question and an exclamatory sentence: "Hey, how can you talk like that? How resonant the voice is! ". With regard to the elders being the interlocutor, the target boy conducts the act of denial mostly for being suspected, while the target boy's denials toward the peers are mostly to express his opposing views. 
Table 5. Denial toward the elder sister.

\begin{tabular}{lll}
\hline Denials & Frequency & Percentages \\
\hline Multimodal denial & 14 & 73.7 \\
Verbal denial & 4 & 21 \\
Non-verbal denial & 1 & 5.3 \\
Total & 19 & 100 \\
\hline
\end{tabular}

Among the 47 cases of denial toward the peers, there are 19 cases of denial toward the elder sister, the frequency of which is the highest compared with other cases with his brother and friends as the interlocutor (s). As can be seen from Table 5, multimodal denial is most frequently used by the target boy, occupying more than two-third of his denial, while the frequency of non-verbal denial remains almost stable, being the least. One possible reason why denials toward the elder sister are the most is that on the one hand, as the oldest child in the family, it is entitled for the elder sister to judge and educate the younger brother. On the other hand, the elder sister has better performances in school than the boy, as a result of which she is praised by the elders more often, while the target boy is more criticized. When two of them do the same wrong thing, the mother tends to criticize the target boy rather than the elder sister. This imbalance may be another contextual factor that affects the frequency of the target boy's denial toward the elder sister.

In Example 6, the elder sister threw things around the house to test how her stepmother would treat her, but her stepmother was very tolerant and friendly to her. Later, the target boy did the same thing, and then his sister began to criticize him, which the target boy didn't accept. In this example, the target boy expressed his denial through an emphatic sentence, facial expressions (frowning and pouting) and a deictic gesture (pointing to his sister). On the one hand, simultaneous application of verbal and nonverbal sources frowning and pouting realizes an equivalent relationship. On the other hand, when the boy says the word "she" with fingering his elder sister, the verbal expression and gesture build up a complementary relationship with each other. In this example, facial expressions and gesture are used to strengthen the denial of verbal expressions as the main semiotic channel.

\section{Example 6}

Sister: I am just doing what a sister should do, but they are making trouble for me.

The target boy: It was SHE who is too overbearing.

Multimodal: Fingering to the sister.

Frowning and pouting.

In Example 7, the target boy and his younger brother kept in mind to be amicable to each other as their parents told them to, so they were responsive to their new neighbors and even lent their father's personal razor. The elder sister called them two fools, then the target boy employed the rhetorical device of repetition accompanied by a facial expression and body movements in a similar rhythmic punch to express his denial. These rhythmic body movements are combined with the same rhythmic utterances to reinforce verbal denial, which forms a supplementary semiotic interactional relationship.

Example 7

Sister: You two fools, listen to me.
The target boy: We are not fools. We are not fools.

Multimodal: Frowning.

Making fists with both hands.

Right and left hands punching in sequence.

In Example 8, while the interior decoration of the target boy's family was modern style, his grandfather bought a mirror with red flowers and green leaves and placed it in an outstanding place. His sister felt that it was not in line with the style of the family, then the target boy denied his sister with a rhetorical question and a simple sentence. In this example, denial is realized by use of a rhetorical question and a judgement without any negating expressions.

\section{Example 8}

Sister: The mirror our grandfather bought is ugly.

The target boy: Why is the mirror ugly? It's so colorful.

In Example 9, the sister asked the target boy to do some voluntaries in the community when the target boy said he had a stomachache and squatted on the ground unwilling to get up to work, and then his sister complained that he always made excuses when being required to do chores. In this example, the target boy made use of an eye gaze of direct angry glare to express denial.

Example 9

Sister: Whenever the community has voluntary labor, you will have a stomach and toothache.

The target boy: Turned to glare at her angrily

Table 6. Denial toward the younger brother.

\begin{tabular}{lll}
\hline Denials & Frequency & Percentages \\
\hline Multimodal denial & 12 & 70.6 \\
Verbal denial & 5 & 29.4 \\
Non-verbal denial & 0 & 0 \\
Total & 17 & 100 \\
\hline
\end{tabular}

Table 6 shows the target boy's denial toward the younger brother. Among the 47 cases of denial toward the peers, there are 17 denials toward the younger brother, in which there are 0 case of non-verbal denial, 5 cases of verbal denial and 12 cases of multimodal denial. In other words, the number of denial to the younger brother is close to that toward both the elder sister and the stepfather.

In Example 10, the target boy became obsessed with cloning technology and immersed himself in the Three Thousand Questions about Clone, but it didn't take long for the target boy to become confused of the content. When his stepfather came to investigate, the younger brother told the truth, but the target boy refused to admit it and denied with a rhetorical question and a statement.

Example 10

Younger brother: He nodded off right after seeing the third question.

The target boy: Who did nod off? I am awake.

In Example 11, the target boy's grandfather woke up in the morning and found that the toilet light had been on, and then the grandfather asked who forgot to turn it off the night before. Whenever some bad things like this happened, everyone instantly thought that the target boy did it for getting into mischief being his image. When the grandfather asked the 
younger brother who did that, the younger brother immediately said that it was the target boy, when the latter made use of a rhetorical question accompanied with the facial expression frowning which helps to express denial. In this example, the two modals present an equivalent relationship.

Example 11

Younger brother: Liu Xing forgot to turn off the light in the toilet last night.

The target boy: Who said so?

Multimodal: Frowning.

Table 7. Denial toward friends.

\begin{tabular}{lll}
\hline Denials & Frequency & Percentages \\
\hline Multimodal denial & 7 & 63.6 \\
Verbal denial & 3 & 27.3 \\
Non-verbal denial & 1 & 9.1 \\
Total & 11 & 100 \\
\hline
\end{tabular}

There are 11 cases of the target boy's denial toward his friends, in which multimodal denial is still the most frequently used, followed by verbal denial, and there is only one case of non-verbal denial.

In Example 12, the target boy wanted to sell the tennis racket of his family to his friend A to buy shoes worth 500 Chinese yuan, but his friends had only 499 yuan at that time. When his friend said that the lack of one Chinese yuan is no big deal, the target boy used an emphatic sentence to express his denial.

\section{Example 12}

Friend A: Are you short of this one yuan?

The target boy: It's not me that is short of one yuan. It's the shopping mall which requires 500 yuan exactly.

In Example 13, friend A came to play with the target boy. Seeing that the target boy's eyes were swollen, friend A laughed at him. Being ashamed of admitting that, the target boy used a non-verbal denial, that is, chasing out friend A with a broom to express his denial. This is also one of the few non-verbal denials.

\section{Example 13}

Friend A: Look at your swollen eyes, how many tears you have to shed.

The target boy: Take a broom to drive him away.

In Example 14, friend $\mathrm{A}$, wearing a pair of new shoes and showing off ostentatiously, came to the target boy who then used two rhetorical questions and an imperative sentence as dominant sources to deny that he was not jealous of his friend. In the meantime, he glanced at the friend, the facial expression of which expresses displeasure. In this example, the facial expression reinforces the denial effect of verbal resources.

\section{Example 14}

Friend A: You are jealous.

The target boy: Who is jealous? Isn't it just a pair of torn shoes? Don't be proud.

Multimodal: Glancing at the friend.

\subsubsection{The Multimodal Representation of the Target Boy's Denial Toward the Non-relatives}

There are only 2 cases of the target boy's denials toward the non-relatives out of 110 denials. One possible reason may be that the interaction between the target boy and non-relatives were rare in the first place.

In Example 15, the target boy helped his grandmother find an old comrade in arms. As a result, it was a wrong person that was found, so the comrade in arms complained that the boy was unreliable. In this example, the target boy uses facial expression to deny, which is a non-verbal denial.

Example 15

Non-relative 1: As soon as I look at Mr. Liu, I know that this is not true.

The target boy: Frowning and pouting.

\subsection{The Characteristics of Multimodal Interaction}

Table 8. Relationship of multimodal denials.

\begin{tabular}{lll}
\hline Multimodal denial & Frequency & Percentages \\
\hline Equivalent relationship & 66 & 66 \\
Complementary relationship & 17 & 17 \\
Supplementary relationship & 17 & 17 \\
Total & 100 & 100 \\
\hline
\end{tabular}

Table 8 manifests that the number of the equivalent relationship is highest among 82 cases of multimodal denial, accounting for $66 \%$. The complementary and supplementary relationships make up $17 \%$ of the total respectively.

In example 16 , the target boy paid nine yuan salary every day to his tutor who toke him outside to play rather than teaching him knowledge of books. His younger brother reckoned the tutor was a fabulous teacher. The target boy in this example uses a rhetorical question and a syntactically complete sentence as dominant resources to deny that the tutor is not good. At the same time, he employs the facial expression frowning that conducive to expressing denial. The verbal sources and facial expression present an equivalent relationship.

Example 16

Younger brother: How nice Mr. Yuan is. He takes us to play every day.

The target boy: What's good about him? He takes nine yuan from me for nothing every day.

Multimodal: Frowning.

\section{Conclusion}

Based on video corpus drawn from a classical sit-com, this quantitative study analyzes the multimodal characteristics of Chinese children's denial through observing 110 cases of multimodal denial acts with a 14-year-old Mandarin-speaking boy as a case study. Conclusions can be drawn from the above analysis:

Regardless of different interlocutors, the target 14-year-old boy often conducts multimodal denial, that is, a combination of verbal sources, facial expressions, body movements, and gestures, etc. However, the frequency of denial toward different interlocutors varies. The denials toward the elders are the most. In contrast, denials toward the peers are less common and there are only 2 cases of denial toward the 
non-relatives. Looking closely at the target boy's denial toward different interlocutors, denials toward the mother occur most frequently while the numbers of the denial toward other family members don't show sharp differences. Denials toward his friends are intermediate while denials toward others like the biological father, the grandfather and grandmother, neighbors and strangers are rather rare. Besides, the content between the denials toward the elders and those toward the peers also differ, with the former being mainly about denial of unjust blames from the elders and the latter being about denial of misjudgment. With regard to multimodal interaction, the target boy tends to employ multimodal resources simultaneously which enhances the communicative force of denial.

What was concluded above leaves us some enlightening ideas about the ways of parent-child education and interaction:

Firstly, parental attention must be paid to children's frequent multimodal acts like multimodal denials under discussion in this study as by doing so, parents are more likely to accurately evaluate the intension of children's behaviors and respond more appropriately, considering that the communicative force of a multimodal act obviously differs from a mono-modal one.

Secondly, it may benefit and stimulate positive parent-child interaction if parents try to make use of both verbal and nonverbal resources to express their intentions as multimodal communication is quite common for teenagers. For example, parents may use facial expressions such as frowning, glancing, and gestures like pointing at something to conduct the act of denials rather than mere verbal questioning, etc.

Though analyzing multimodal denial act of the 14 years old Mandarin-speaking boy through observing 110 cases with considering the target boy's disposition and relationship with interlocutors, the study still has some shortcomings, such as without thinking about the impact of gender differences and more samples. Future research can expand the number of data, compare children of different ages and genders, and study the influence of other factors on children's multimodal denial act.

\section{Acknowledgements}

This research is a component of the 2018 research project "Video-corpus-based Study of Chinese-speaking Children's Multimodal Negating Act and Its Development" (18CYY022) sponsored by the National Social Science Foundation of China.

\section{References}

[1] Victor Ho. (2021). Denial in managerial responses: Forms, targets and discourse environment. Journal of Pragmatics, 176, 124-136.

[2] Collins coBUILD. (2017). Collins coBUILD advanced learner's English-Chinese dictionary (8th edition). Foreign language teaching and research press, 520 .
[3] Horn, Lawrence R. (1985). Metalinguistic negation and pragmatic ambiguity. Language, 61, 121-174.

[4] Chua, A. \& Banerjee, S. (2018). Intentions to trust and share online health rumors: An experiment with medical professionals. Computers in Human Behavior, 87, 1-9.

[5] Tanaka, Y., Sakamoto, Y. \& Matsuka, T. (2013). Toward a social-technological system that inactivates false rumors through the critical thinking of crowds. Proceedings of the Hawaii international conference on system sciences, 649-658. New York, NY: IEEE.

[6] Clayton, R. B., Ozturk, P., Li, H., \& Sakamoto, Y. (2015). Combating rumor spread on social media: The effectiveness of refutation and warning. Proceedings of the Hawaii international conference on system sciences, 2406-2414. New York, NY: IEEE.

[7] Spenader a, Emar Maier. (2009). Contrast as denial in multi-dimensional semantics Jennifer. Journal of Pragmatics, 41, 1707-1726.

[8] Van der Sandt, R. (1991). Denial. Papers from the Chicago Linguistics Society: Parasession on Negation. CLS, Chicago, 27, 331-344.

[9] Van der Sandt, R., (1988). Context and Presupposition. Croom Helm Ltd, London.

[10] John T. Kearns. (2006). Conditional assertion, denial, and supposition as illocutionary acts. Linguist Philos, 29, 455-485.

[11] Eleonore Oversteegen, Joost Schilperoord. 2014. Can pictures say no or not? Negation and denial in the visual mode. Journal of Pragmatics, 67, 89-106.

[12] Bressem, J. \& Müller, C. (2014). Body Language Communication: An International Handbook on Multimodality in Human Interaction. Berlin: Degruyter Mouton Press.

[13] Bressem, J., Stein, N., \& Wegener, C. (2017). Multimodal Language Use in Savosavo. Pragmatics, 2, 173-206.

[14] Halliday, M. A. K. (1973). Explorations in the Functions of Language. London: Edward Arnold.

[15] Halliday, M. A. K. (1978). Language as a Social Semiotic: The Social Interpretation of Language and Meaning. London: Edward Arnold.

[16] Halliday, M. A. K. (2007). The notion of "context" in language education. Language and Education. London \& New York: Continuum, 269-290.

[17] Matthiessen. C. M. I. M. (2007). The multimodal page: A systemic functional exploration. New Directions in the Analysis of Multimodal Discourse. Mahwah: Lawrence Erlbaum and Associates, 1-62.

[18] Delu Zhang. (2018). Context of Situation in Multimodal Text. Journal of PLA University of Foreign Languages. 3, 1-9.

[19] Capirci O, Iverson M J, et al. (1996). Gestures and words during the transition to two word speech. Journal of Child Language, 23, 645-673.

[20] Rongbin Wang, Rui Zhang. (2020). The Multimodal Representational Characteristics of Mandarin Children's Disagreement - A Case Study Based on Diachronic Videos. International Journal of Language and Linguistics, 8 (3): $115-121$. 
[21] Carey Jewitt, Jeff Bezemer and Kay O'Halloran. (2017). Introducing multimodality. London: Rouledge press.

[22] Beaupoil-H, P., Morgenstern, A. \& D. Boutet. (2016). A child's multimodal negations from 1 to 4: The interplay between modalities [A]. In P. Larrivée \& C. Lee (eds.). Negation and Polarity: Experimental Perspectives [C]. Switzerland: Springer, 95-123. 